\title{
Antenatal Magnesium Sulphate (Mgso4) for Fetal Neuro- Protection Prior to Preterm Labor: Mini-Review
}

\author{
Mohannad Abu-Faza1, Ibrahim A. Abdelazim**1,2 \\ ${ }^{I}$ Department of Obstetrics, and Gynecology, Ahmadi Hospital, Kuwait Oil Company (KOC), Kuwait \\ ${ }^{2}$ Department of Obstetrics, and Gynecology, Ain Shams University, Cairo, Egypt
}

*Corresponding Author: Ibrahim A. Abdelazim, Department of Obstetrics, and Gynecology, Ahmadi Hospital, Kuwait Oil Company (KOC), Kuwait, Department of Obstetrics, and Gynecology, Ain Shams University, Cairo, Egypt.Email: dr.ibrahimanwar@gmail.com

\begin{abstract}
Background: Cerebral palsy $(C P)$ is a motor and/or cognitive dysfunction affecting the low birth weight $(L B W)$ infants, and infants delivered preterm before 34 gestational weeks:. Authors recommended the Magnesium Sulphate (MgSO4) infusion for prevention of CP in preterm infants delivered before 34 gestational weeks:

Objectives: This mini-review article designed to highlight the value of antenatal Magnesium Sulfate (MgSO4) infusion before 34 gestational weeks` in reduction of the cerebral palsy incidence associated with preterm labor (PTL), and low birth weight $(L B W)$.

Materials and Methods: A PubMed search done between 2002 to 2009 using the words; Mg Sulphate (MgSO4), and fetal neuro-protection. The retrieved articles were critically analyzed to highlight the value of antenatal Magnesium Sulfate (MgSO4) infusion before 34 gestational weeks' in reduction of the cerebral palsy incidence associated with preterm labor (PTL), and low birth weight (LBW).

Results: Conde-Agudelo et al, found that the MgSO4 infusion to women at risk of labor before 34 weeks reduces the risk of $C P$, without any significant maternal side effects or complications ${ }^{[l]}$. In addition; Rouse et $a l$, reported that the $\mathrm{MgSO4}$ reduced the risk of moderate or severe $\mathrm{CP}$ in infants of singleton pregnancies (RR 0.52, CI; 0.27-0.98) ${ }^{[2]}$.

Recently; Doyle et al, meta-analysis reported that the antenatal MgSO4 infusion before 37 gestational weeks to women at risk of PTL associated with reduced CP risk (RR 0.68, CI; 0.54-0.87), and gross motor disabilities (RR 0.61, CI; 0.44-0.85) in their children (RR 1.04, CI; 0.92-1.17) ${ }^{[3]}$.
\end{abstract}

Conclusion: Ante-natal MgSO4 infusion before 34 gestational weeks`could be useful in cerebral palsy prevention in preterm infants, without any significant maternal side effects or complications.

Keywords: MgSO4, Neuroprotection, CP, PTL.

\section{INTRODUCTION}

Cerebral palsy (CP) is a motor and/or cognitive dysfunction affecting the low birth weight (LBW) infants, and infants delivered preterm before 34 gestational weeks ${ }^{[4]}$.

Many authors recommended the Magnesium Sulphate (MgSO4) infusion for prevention of $\mathrm{CP}$ in preterm infants delivered before 34 gestational weeks` ${ }^{[5]}$.

Although; Magpie trial, concluded that the lower risk of eclampsia following prophylaxis with $\mathrm{MgSO} 4$ was not associated with a clear decrease in the risk of death or disability for infants at 18 months ${ }^{[6]}$. A Cochrane meta- analysis reported that the antenatal $\mathrm{MgSO} 4$ infusion before 37 gestational weeks to women at risk of PTL associated with reduced CP risk in their children (RR 0.68, CI; 0.54-0.87) ${ }^{[3]}$.

So; this mini-review article designed to highlight the value of antenatal Magnesium Sulfate (MgSO4) infusion before 34 gestational weeks` in reduction of the cerebral palsy incidence associated with preterm labor (PTL), and low birth weight (LBW).

\section{MATERIALS AND MethodS}

A PubMed search done between 2002 to 2009 using the words; $\mathrm{Mg}$ Sulphate (MgSO4), and fetal neuro-protection. The retrieved articles 
were critically analyzed to highlight the value of antenatal Magnesium Sulfate (MgSO4) infusion before 34 gestational weeks` in reduction of the cerebral palsy incidence associated with preterm labor (PTL), and low birth weight (LBW).

The exact mechanism of neuro-protection following antenatal $\mathrm{MgSO} 4$ is not known but the following pathways have been suggested;

a. MgSO4 down regulates excitatory stimuli, by blocking N-methyl-D-aspartate receptor (NMDA) receptors in the brain ${ }^{[7-9]}$.

b. MgSO4 improves the cerebral blood flow.

c. $\mathrm{MgSO} 4$ prevents cytokines involved in PTL from producing neuronal injury.

d. MgSO4 have an anti-apoptotic effect on the neuronal cells ${ }^{[7-9]}$.

$\mathrm{MgSO} 4$ achieve fetal neuro-protection, and indicated before 30 weeks' $(<29+6$ weeks) to women who are at imminent risk of PTL, or women with planned or definitely expected PTL within 24 hours or women in active PTL (MgSO4 given 4 hours prior to delivery).

$\mathrm{MgSO} 4$ for neuro-protection given for women at risk of PTL before $29+6$ gestational weeks, irrespective their pregnancy is singleton or multiple, and irrespective corticosteroids given or not in the current pregnancy.

$\mathrm{MgSO} 4$ infusion for neuro-protection of no value if given after 30 gestational weeks' or given for women not at risk PTL and/or LBW.

$\mathrm{MgSO} 4$ regimen for fetal neuro-protection is 4 grams over 20 minutes (loading dose), followed by maintenance dose of 1 gram/hour for 4 hours.

Before MgSO4 infusion;

a) The PTL should confirmed using; transvaginal cervical length assessment (TVCL), and fetal fibronectin (fFN) test. The absence of fFN in the cervical secretions is very useful negative predictor of imminent PTL (negative predictive value for birth within 7 days is $97-98 \%$ ).

b) Confirm the gestational age using; early ultrasound scan done before 20 weeks' gestation, and first day of last menstrual (LMP) ${ }^{[10-12]}$.

c) Determine imminent labor; evidence of cervical effacement, and dilatation, ongoing contractions which are not relieved with tocolysis in women less than 30 gestational weeks'. d) $\mathrm{MgSO} 4$ infusion given in the labor room, combined with the management of the PTL according to hospital protocol ${ }^{[3]}$.

e) The MgSO4 infusion should combine with assessment of fetal and maternal wellbeing.

f) Clinical care of the woman, and fetus according to the hospital protocol.

g) The MgSO4 infusion should started 4 hours before the anticipated delivery time.

The MgSO4 infusion solution used is 8 grams of $\mathrm{MgSO} 4$ in a $100 \mathrm{ml}$ prepackaged solution given through infusion device (women only receive 50 $\mathrm{ml}=4$ grams of $\mathrm{MgSO} 4)^{[3,1]}$.

Administer intravenous loading bolus dose of 4 grams of $\mathrm{MgSO} 4$ over 20 minutes via a controlled infusion device $(150 \mathrm{ml} /$ hour for 20 minutes) ${ }^{[1]}$.

The loading dose is followed by a maintenance infusion of 1 gram of $\mathrm{MgSO} 4$ per hour for 4 hours (infusion rate of $12.5 \mathrm{ml}$ per hour) ${ }^{[1]}$.

Prior to the of $\mathrm{MgSO} 4$ infusion ensure: presence of patellar reflexes, respiratory rate more than $12 / \mathrm{min}$, and correct medication, and infusion rate.

Calcium gluconate 1 gram in $10 \mathrm{ml}(2.2 \mathrm{mmol}$ calcium in $10 \mathrm{ml}$ ) must be available for treatment of $\mathrm{MgSO} 4$ toxicity ${ }^{[1]}$.

Patellar reflexes should check every 15 minutes for the first 2 hours of $\mathrm{MgSO} 4$ infusion, then hourly. Stop the infusion, and collect blood for serum Magnesium levels if the patellar reflex absent at any time during the infusion.

Monitor the respiratory rate every 15 minutely during the first 2 hours of MgSO4 infusion, then hourly. Stop the infusion, collect blood for serum Magnesium levels, maintain patent airway with Oxygen 6-8 liters/minute, followed by intravenous Calcium gluconate slowly, and monitor the heart rate with an ECG, if the respiratory rate was less than 12 per minute at any time during the infusion.

Monitor the Oxygen saturation levels hourly during the infusion. Stop the infusion, collect blood for serum Magnesium levels, call a code blue medical, and initiate respiratory support until the woman is intubated, and ventilated, in case of respiratory arrest during the infusion.

Measure and record urine output hourly during MgSO4 infusion. Stop the infusion, collect blood for serum Magnesium levels, and call 
medical staff, in case the urine output decreased during the infusion.

Monitor the blood pressure every 15 minutes during $\mathrm{MgSO} 4$ infusion hourly, and report any side effects related to $\mathrm{MgSO} 4$ infusion.

\section{ReSUlts}

Conde-Agudelo et al, found that the $\mathrm{MgSO} 4$ infusion to women at risk of labor before 34 gestational weeks' reduces the risk of $\mathrm{CP}$, without any significant maternal side effects or complications ${ }^{[1]}$. In addition; Rouse et al, reported that the $\mathrm{MgSO} 4$ reduced the risk of moderate or severe $\mathrm{CP}$ in infants of singleton pregnancies (RR 0.52, CI; 0.27-0.98) ${ }^{[2]}$.

Recently; Doyle et al, meta-analysis reported that the antenatal MgSO4 infusion before 37 gestational weeks' to women at risk of PTL associated with reduced CP risk (RR 0.68, CI; $0.54-0.87$ ), and gross motor disabilities (RR $0.61, \mathrm{CI} ; 0.44-0.85)$ in their children without affecting the pediatric mortality (RR 1.04, CI; $0.92-1.17)^{[3]}$.

\section{DISCUSSION}

Cerebral palsy has a prevalence of 2:1000 live births, and the principal obstetric risk factors for CP are PTL before 34 gestational weeks`, and LBW.

$\mathrm{MgSO} 4$ administration to the preterm fetus has been linked with the prevention of $\mathrm{CP}$ since 1995.

Although; Crowther et al, found that the $\mathrm{MgSO} 4$ had no a significant effect on the risk of CP in both infants of singleton pregnancies (RR 1.01, CI; 0.61-1.68), and infants of multiple gestations (RR 0.52, CI; 0.21-1.25) ${ }^{[13]}$.

Conde-Agudelo et al, found in their systematic review, that the $\mathrm{MgSO} 4$ infusion to women at risk of labor before 34 gestational weeks reduces the risk of $\mathrm{CP}$ without any significant maternal side effects or complications $(70 \%$ of women reported minor side effects including; flushing, pain at the injection site, and sweating) [1].

In addition; Rouse et al, reported that the $\mathrm{MgSO} 4$ associated with reduction of moderate or severe CP in singleton pregnancies (RR 0.52, CI; 0.27-0.98) but not in twin pregnancy ${ }^{[2]}$.

Recently; Doyle et al, meta-analysis reported that the antenatal MgSO4 infusion before 37 gestational weeks' to women at risk of PTL associated with reduced CP risk (RR 0.68, CI;
0.54-0.87), and gross motor disabilities (RR $0.61, \mathrm{CI} ; 0.44-0.85)$ in their children without affecting the pediatric mortality (RR 1.04, CI; $0.92-1.17)^{[3]}$.

In the Magpie trial, which concluded that the lower risk of eclampsia following prophylaxis with $\mathrm{MgSO} 4$ was not associated with a clear decrease in the risk of death or disability for infants at 18 months ${ }^{[6]}$, the time of $\mathrm{MgSO} 4$ infusion was unclear, and the assessment of $\mathrm{CP}$ done at 18 months of age. However; preterm infants, have a lot of neurologic manifestations in the first months of age, which resolve later, and diagnosed wrongly as $\mathrm{CP}^{[1,14]}$. Therefore, it was suggested that the diagnosis of $\mathrm{CP}$ should assigned cautiously before 24 months of age unless the disorder is exceptionally severe ${ }^{[1,15]}$.

No limitations were faced during conduction of this mini-review article. Future comparative studies needed to confirm the role of $\mathrm{MgSO} 4$ in $\mathrm{CP}$ prevention in preterm infants, especially after increased incidence of multiple pregnancies, and PTL with the assisted artificial techniques (ARTs). This mini-review article concluded that the ante-natal $\mathrm{MgSO} 4$ infusion before 34 gestational weeks' could be useful in in reduction of the cerebral palsy incidence associated with preterm labor (PTL), and low birth weight (LBW).

Conclusion: Ante-natal MgSO4 infusion before 34 gestational weeks` could be useful in cerebral palsy prevention in preterm infants, without any significant maternal side effects or complications.

\section{REFERENCES}

[1] Conde-Agudelo A, Romero R. ANTENATAL MAGNESIUM SULFATE FOR THE PREVENTION OF CEREBRAL PALSY IN PRETERM INFANTS <34 WEEKS' GESTATION: A SYSTEMATIC REVIEW AND META-ANALYSIS. Am J Obstet Gynecol. 2009 June; 200(6): 595-609. doi: 10.1016/j.ajog.2009.04.005. [PubMed]

[2] Rouse DJ, Hirtz DG, Thom E, Varner MW, Spong CY, Mercer BM, et al. A randomized, controlled trial of magnesium sulfate for the prevention of cerebral palsy. N Engl J Med. 2008; 359:895-905. doi: 10.1056/NEJMoa 0801187. [PubMed]

[3] Doyle LW, Crowther CA, Middleton P, Marret $\mathrm{S}$, Rouse D. Magnesium sulphate for women at risk of preterm birth for neuro protection of the fetus. Cochrane Database Syst Rev. 2009; (1): CD004661. doi: 10.1002/14651858. CD00466 1. pub3. [PubMed] 
[4] Himpens E, Van den Broeck C, Oostra A, Calders P, Vanhaesebrouck P. Prevalence, type, distribution, and severity of cerebral palsy in relation to gestational age: a meta-analytic review. Dev Med Child Neurol. 2008; 50:334340. doi: 10.1111/j.1469-8749.2008.02047.x. [PubMed]

[5] Matsuda Y, Kouno S, Hiroyama Y, Kuraya K, Kamitomo M, Ibara S, Hatae M. Intrauterine infection, magnesium sulfate exposure and cerebral palsy in infants born between 26 and 30 weeks of gestation. Eur J Obstet Gynecol Reprod Biol. 2000 Aug; 91(2):159-64. [PubMed]

[6] Magpie Trial Follow-Up Study Collaborative Group. The Magpie Trial: a randomised trial comparing magnesium sulphate with placebo for pre-eclampsia. Outcome for children at 18 months. BJOG. 2007 Mar; 114(3):289-99. 10.1111/j.1471-0528.2006.01165.x. [PubMed]

[7] Salter MG, Fern R. NMDA receptors are expressed in developing oligodendrocyte processes and mediate injury. Nature. 2005;438 (7071):1167-1171. doi:10.1038/nature04301. [PubMed]

[8] Micu I, Jiang Q, Coderre E, Ridsdale A, Zhang $\mathrm{L}$, Woulfe $\mathrm{J}$, et al. NMDA receptors mediate calcium accumulation in myelin during chemical ischaemia. Nature. 2006;439 (7079): 988-992. doi:10.1038/nature04474. [PubMed]

[9] Johnston MV, Nakajima W, Hagberg H. Mechanisms of hypoxic neurodegeneration in the developing brain. Neuroscientist. 2002; 8 (3):212-220. doi:10.1177/1073858402008003 007. [PubMed]
[10] Abdelazim IA, Abdelrazak KM, Al-Kadi M, Yehia AH, Abdulkareem AF. Fetal fibronectin (Quick Check fFN test) versus placental alpha microglobulin-1 (AmniSure test) for detection of premature rupture of fetal membranes. Arch Gynecol Obstet. 2014; 290(3):457-64. doi: 10.1007/s00404-014-3225-5. [PubMed]

[11] Abdelazim IA. Insulin-like Growth Factor Binding Protein-1 (Actim PROM test) for detection of premature rupture of fetal membranes. J Obstet Gynaecol Res. 2014 Apr; 40(4):961-7. doi: 10.1111/jog.12296. [PubMed]

[12] Abdelazim IA, Makhlouf HH. Placental alpha microglobulin-1 (AmniSure test) versus Insulin-like growth factor binding protein-1 (Actim PROM test) for detection of premature rupture of fetal membranes. J Obstet Gynaecol Res. 2013; 39(6): 1129-36. doi: 10.1111/jog. 12045. [PubMed]

[13] Crowther CA, Hiller JE, Doyle LW, Haslam RR. Australasian Collaborative Trial of Magnesium Sulphate (ACTOMg SO4) Collaborative Group. Effect of magnesium sulfate given for neuroprotection before preterm birth: a randomized controlled trial. JAMA. 2003; 290 (20): 2669-2676. doi: 10.1001/jama.290.20.2669. [PubMed]

[14] Bracewell M, Marlow N. Patterns of motor disability in very preterm children. Ment Retard Dev Disabil Res Rev. 2002;8 (4):241248.doi:10.1002/mrdd.10049. [PubMed] .

[15] Paneth N. Establishing the diagnosis of cerebral palsy. Clin Obstet Gynecol. 2008;51 (4):742748. doi: 10.1097/GRF.0b013e318187081a. [PubMed]

Citation: Mohannad Abu-Faza, Ibrahim A. Abdelazim, Antenatal Magnesium Sulphate (MgSO4) for Fetal Neuro-Protection Prior to Preterm Labor: Mini-Review. ARC Journal of Gynecology and Obstetrics. 2017; 2(2):11-14. doi:dx.doi.org/10.20431/2456-0561.0202003.

Copyright: (C) 2017 Authors. This is an open-access article distributed under the terms of the Creative Commons Attribution License, which permits unrestricted use, distribution, and reproduction in any medium, provided the original author and source are credited. 